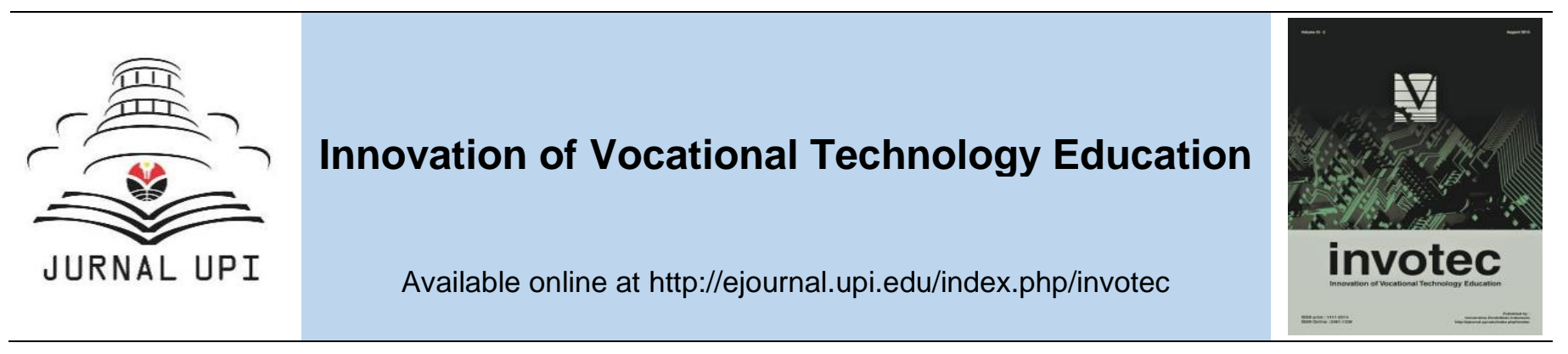

\title{
Hazard Analysis Critical Control Point (HACCP) in Sweet Potato's Liquid Sugar
}

\author{
Ai Mahmudatussa'adah \& Sudewi
}

Universitas Pendidikan Indonesia, Indonesia

ARTICLE INFO

Article history:

Received 05 Juni 2016

Received in revised form 08 July

2016

Accepted 22 July 2016

Available online 31 August 2016

Keywords:

Liquid sugar

Sweet potato

critical control ponit

Corresponding author:

aims@upi.edu
A B STRACT

To ensure the safety of food products to the consumer, required the application of Hazard Analysis Critical Control Point (HACCP). Liquid sugar is a food product which can be eaten directly or used as additives in the processing of other products. Stages in the HACCP plan includes identification of hazard analysis critical control point (CCP), the determination of the limit of danger, CCP monitoring, corrective action against danger verification, and documentation. Results of hazard identification no physical harm in the form of pebbles, hair; pesticide chemical hazards, biological hazards ants and black shank. CCP 1 was washing materials, CCP 2 was incubation, CCP 3 was Packaging. Critical limits for all hazards should be zero. Corrective measures must be of good quality raw materials. Wash in running water. Incubation at $400 \mathrm{C}$. Packaging using sterile packaging.

\section{Introduction}

Assurance of food safety is a major factor that must be considered in the development of a food product. Food safety is an important issue in the field of food and needs special attention in food monitoring program. Food monitoring by relying on end product testing cannot guarantee the safety of the product and if found unsafe food, but can be harmful to consumers, can also cause huge economic losses for producers. Thus, to ensure the safety of food products developed, should be the implementation of preventive methods, namely the implementation of food safety assurance system HACCP (Hazard Analysis Critical Control Point) (Hung et al., 2015). The application of HACCP can provide a positive influence on the quality of the end product and can provide security for consumers (Kokkinakis, et al., 2008; Domenech, et al., 2013; Lu, et al., 2014; Hung et al., 2015).

HACCP food safety assurance system is an effective preventive action to ensure food safety. These systems identify the various hazards that may arise during the preparation, processing, packaging and distribution. HACCP is a system of controls to prevent the danger that is based on hazard identification, determination of critical control points hazard (CCP), the determination of the limit of danger (CL), monitoring of CCP, and an act of correction, verification, and documentation. HACCP was developed to 
ensure food safety with a preventive approach (preventive) so as to provide guarantees to produce safe food for consumers.

The application of HACCP in the food industry is closely tied to the implementation of Good Manufacturing Practices (GMP) and Sanitation Standard Operating Procedure (SSOP) (Jeng et al., 2005). GMP ensures the implementation of food making is in the proper procedures, and SSOP ensure that the application of standardization sanitary hygiene standards are applied properly. Some of the advantages that can be obtained by a food industry application of HACCP systems include improving food safety in the food products produced, increase customer satisfaction so that the complaints of consumers will be reduced, improving the function of control, changing the approach to the final testing retrospective nature to approach quality assurance preventive, and reduce waste and damage to the product or waste.

\section{Method}

Stages in the HACCP plan includes identification of hazard analysis critical control point (CCP), the determination of the limit of danger, CCP monitoring, corrective action against danger verification, and documentation.

\section{Results and Discussion}

According to the National Advisory Committee on Microbiological Criteria on Food (1998) has seven basic principles of HACCP. Principle 1 is a hazard analysis. Hazard analysis consists of three steps: hazard identification, determination of preventive measures, and the determination of risk category or significance of a hazard. Thus, the need to prepare a list of raw materials and ingredients used in the process, the process flow diagram that has been verified, and the description and use of products which includes consumer groups and how their consumption, and storage. Principle 2 is determination of Critical Control Point (CCP). Critical control points is defined as a point, step or procedure at which control can be applied and a food safety hazard can be prevented, eliminated or reduced to acceptable limits. Principle 3 is determination of Critical Limit. Critical limit (CL) is a criterion that must be met for any precautionary measures intended to eliminate or reduce the hazard to safe limits. The safe limit will be split between the accepted and rejected, such as the range of tolerance at each CCP. Critical limits are set to ensure that the CCP can be well controlled. Determination of critical limits must be justified, meaning that it has a strong reason why the limit is used and must be validated means in accordance with the requirements set and can be measured. Determining the critical limit is usually done based on the study of literature, government regulations, and experts in the fields of microbiology and chemistry, and CODEX.

To set the CL is strongly associated with the CCP. CCP has various components that must be controlled to ensure product safety. In general, critical limits can be classified into physical limits (temperature, time), the limit of the chemical $(\mathrm{pH}$, salinity), and microbiological limit (the number and types of microbes). Test microbial and chemical test requires considerable time.

Principle 4 is monitoring CCP and CL. Testing and monitoring activities are planned and scheduled observations of the effectiveness of the process of controlling the CCP and $\mathrm{CL}$ to ensure that the $\mathrm{CL}$ ensure product safety. Principle 5 is the establishment of corrective action. Corrective measures would be in the event of deviation from a critical limit a CCP. Corrective actions taken if there are deviations, is highly dependent on the level of risk food products. In highrisk food products, for example, corrective action may include termination of the production process before all the aberration corrected / repaired, or products detained / not marketed and tested for safety. Corrective actions can be carried out include stopping the production process, eliminating rework products and production processes as well as verify every precaution.

Principle 6 is verification that the HACCP system to determine compliance with the HACCP plan set. Verification ensures the suitability and effectiveness of the HACCP plan HACCP. Verification activities include the establishment of scheduled inspections, reexamination of the HACCP plan, CCP records examination, and examination of records deviations and disposition of a visual inspection of activities to observe if the CCP is not controlled. Random sampling written record of verification inspections which determine compliance with the HACCP plan or deviations from plan and corrective actions taken. Verification is done on a regular basis to ensure that the CCP set manageable. Verification is also carried out if there is new information about food safety or in case of poisoning by these products.

Principle 7 is documentation. The documentation includes the written data collection across the HACCP program so that the program can be reexamined and maintained for a specific time period. 
Documentation includes all records regarding the CCP, CL, CL monitoring records, corrective actions taken against irregularities and records verification. This document can be shown to the inspector food if an external audit, and can also be used by the operator. Chronology of manufacture of liquid sugar from sweet potato Cilembu can be seen in Figure 1.

The production process includes the process of glucose syrup suspension, likuifikasi, saccharification, filtering and evaporation (Figure 1). Namely the suspension process or sweet potato starch slurry was added water. Likuifikasi the addition of enzymes amylase and amiloglukosidase into the suspension and then boiled up at a temperature of $80-98^{\circ} \mathrm{C}$ until all of amylose degraded into dextrin. Periodically suspension analyzed the levels of amylose with iodine test and the value DE (dextrose equivalent). When the brown iodine means all of amylose has been degraded into dextrin (DE value 8-14) and the liquefaction process is completed. In the process of saccharification, starch dextrin which has been cooled to $50^{\circ} \mathrm{C}$. This process takes approximately 72 hours. Saccharification process is complete when the existing syrup has reached a DE value of at least $94.5 \%, 65 \%$ transmittance value of color and Brix 34-37. The next stage is filtration. The filtrate is then evaporated. The last stage is evaporation to obtain glucose syrup with a viscosity as desired, namely Brix 43-45 for enzymatic way.

In the manufacture of liquid sugar sweet potato, to obtain liquid sugar product safety is necessary to note from sanitation hygiene raw materials, tools and packaging. Raw materials used are sweet potatoes and thermostable enzymes are amylase enzyme mixture and amiloglukosidase. The tools used incubator. Packaging used a plastic bottle.

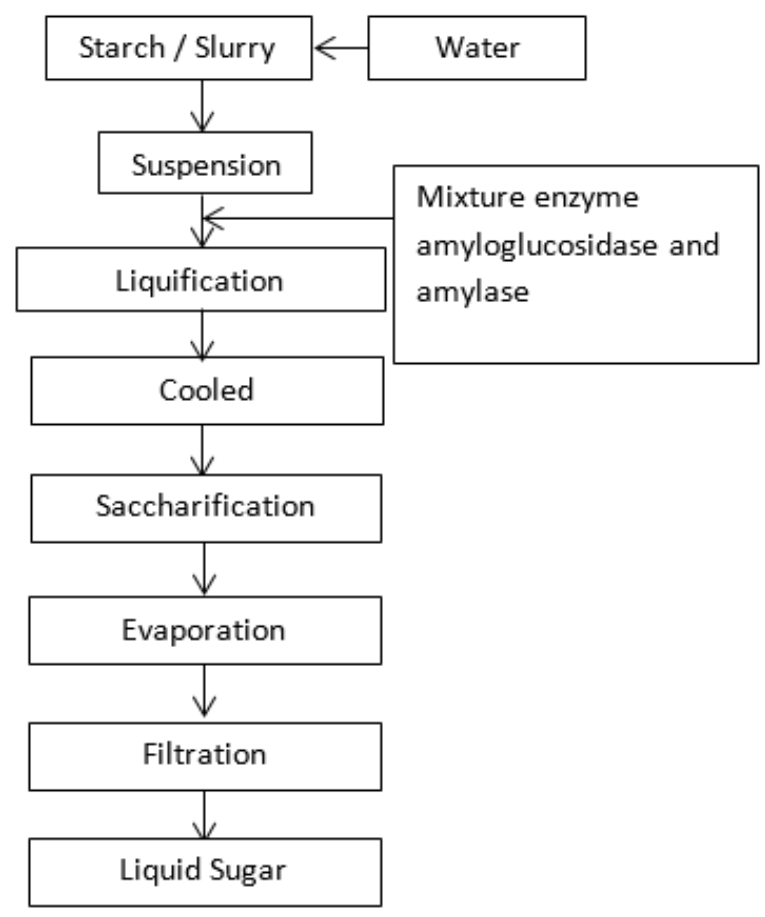

Figure 1. Flow chart of making sweet potato liquid sugar

Results of hazard identification is possible there are physical hazards such as gravel, sand and hair. Chemical hazards such as pesticides, solvents and enzymes. Biological hazards such as ants and black shank. Critical control point (CCP) 1 is the receipt of sweet potatoes and a mixture of enzymes. CCP 2 is in the processing in the form of liquefaction, saccharification, filtering and packaging. At the time of liquefaction must be noted that the temperature used and the type of enzyme used. $100 \mathrm{oC}$ temperature, which is approaching, so that the heat helps breakdown of starch into dextrin. The addition of the enzyme is intended to starch breakdown process becomes faster. The enzyme used must be termostabil.Setelah liquefaction process is a process sakrifikasi, namely dextrin change into simpler sugars components. After the liquefaction process, the temperature is lowered and then added back $30 \%$ of enzymes amylase enzyme mixture and amyloglucosidase are thermostable. After 72 hours the mixture filtered then evaporated again, and the resulting liquid sugar. CCP 3 is the packaging process. All hazards identified are to be zero. Corrective actions taken are the raw materials used should be qualified, and clean. Microorganisms are likely to grow in the liquid sugar is a product that is osmofilik. Microorganisms can arise because of the process of recontamination (Deciu and Antoce, 2014). The HACCP application should be 
monitored from receipt of materials to food products ready for consumption. Washing is done in the flowing water. Using peeler stripping the tazam, clean and hygiene. Stirring during the cooking process. Packaging used must be clean. The application of HACCP in food industry, especially to improve the safety of products produced and improve management (Hung, et al.2015).

\section{Conclusion}

The conclusion of this study: in the planning stages include identification HACCP hazard analysis critical control point (CCP), the determination of the limit of danger, CCP monitoring, corrective action against danger ferifikasi, and documentation. Results of hazard identification no physical harm in the form of pebbles, hair; pesticide chemical hazards, biological hazards ants and black shank. CCP 1 washing materials, 2 incubation CCP, CCP 3 Packaging. Critical limits for all hazards should be zero. Corrective measures must be of good quality raw materials. Wash in running water. Incubation at $400 \mathrm{C}$. Packaging using sterile packaging.

\section{Acknowledgements}

The authors would like to thank the Directorate General of Higher Education, Ministry of Research, Technology and Higher Education, Republic of Indonesia, Indonesia University of Education, for funding this research through Hibah Bersaing research grant 2016.

\section{References}

Deciu, G. \& Antoce, A.O. 2014. Hazard analysis and critical control points system optimization in a starch factory. Scientific Bulletin. Series F. Biotechnologies 18: 249-257.

Domenech E, Amor_os J.A., Escriche I. 2013. Effectiveness of prerequisites and the HACCP plan in the control of microbial contamination in ice cream and cheese companies. Foodborne Pathogens and Disease 10: 222-228.

Hung, Y-T., Liu, C-T., Peng, I-C., Hsu, C., Yu, R-C., Cheng, K-C. 2015. The implementation of a Hazard Analysis and Critical Control Point management system in a peanut butter ice cream plant. Journal of food and drug analysis 23: 509-515

Jeng H.Y. \& Fang J.T. 2003. Food safety control system in Taiwan the example of food service sector. Food Control 14: 317-322.

Kokkinakis E.N., Fragkiadakis G.A., loakeimidi S.H., Giankoulof I.B. \& Kokkinaki A.N. 2008. Microbiological quality of ice cream after HACCP implementation: a factory case study. Czech Journal of Food Sciences 26: 383-391.

Lu J, Pua X.H., Liu C.T., Chang C.L. \& Cheng K.C. 2014. The implementation of HACCP management system in a chocolate ice cream plant. Journal of food and drug analysis 22: 391-398.

National Advisory Committee on Microbiological Criteria on Food. 1998. Hazard analysis and critical control point principles and application guidelines. Journal of Food Protection 61(9):1246-1259. 